\title{
Problems and Countermeasures of Professional Practical Link in the Cultivation of Full-Time Postgraduate with Professional Degree
}

\author{
Qing-Xiu PENG, Lu ZHANG
}

School of Economics and Management, Zhengzhou University of Light Industry, Zhengzhou, China

School of Economics and Management, Zhengzhou University of Light Industry, Zhengzhou, China

pengqingxiu@163.com,949628148@qq.com

Keywords: Professional degree, full-time, professional practice, applied talents.

\begin{abstract}
For full-time postgraduate with professional degree who possess no work experience, the well implementation of professional practice is realization of important link in term of full-time graduate with professional degree cultivation. This paper discourse and analysis from three perspectives, such as the development of Chinese professional degree, the importance of professional practical link and current problems of professional practical link. In order to well implement the practical link and improve the cultivation quality of talents, targeted measures were promoted based on the aforementioned basic.
\end{abstract}

\section{Introduction}

Professional degree was set for following reasons, such as targeting to the needs of certain social areas, cultivation of applied specialized talents with stronger ability of specificity and profession who are able to creatively finish practical work. China officially implemented educational system of professional degree in 1991. From 1996 to 2009, the reason of setting professional degree was to satisfy the education received needs of social on-job personal, so the targeted subjects required certain degree of work experience. The education ministry decided to recruit full-time postgraduate with professional degree which majority is fresh graduates in 2009, and clearly put forward the enlargement of high-level applied talents, especially the cultivation scale of full-time postgraduate with professional degree. Thus far, the recruitment subject of postgraduate with professional degree transformed from non-full-time on-job personal to full-time fresh graduate. By 2020, the quantity of students in school of postgraduate with professional degree accounts for $50 \%$ of total quantity of postgraduate. The overall pattern which postgraduate with professional degree and postgraduate with academic degree each account for half of the total quantity of all the postgraduate would be finalized.

The importance of professional practical link in education of full-time postgraduate with professional degree

Several suggestions about well implementation of cultivation work to full-time postgraduate with professional degree which issued in 2009 puts forward outline guidance to the cultivation mode of full-time postgraduate with professional degree in terms of the cultivation purposes, 
educational requirements, practical requirements and academic thesis requirements of postgraduate with professional degree and clearly points out that its cultivation purpose is "high-level applied specialized talents", the professional practice is important educational link, sufficient professional practice with high quality is important guarantee to the education quality of professional degree. Before 2008, postgraduate with professional degree has mainly adopted the "In university while On job” non-full-time education measure. Its applicant source basically all came from the front line of manufacture and practice. During the process of cultivation, university pays more attention upon the studying of professional curriculum. University have no participation in term of professional practice link, student basically complete solely in their work position. While the majority of full-time postgraduate with professional degree is fresh graduate who seriously lacks practical work experience and with little ability of engineer practice. Without insufficient and specialized practical ability in high quality, the "high-level applied specialized talents" can't be cultivated for those full-time postgraduate without any work experience. Thus, well implementation is important of professional practical link is the most important to the cultivation of full-time postgraduate with professional degree.

\section{The existing problems and main form of professional practical link}

Different from undergraduate whose main goal is the familiarization of basic work process and work requirements of their own job area, general practice which aim to expend their social experience. The professional practical link of full-time postgraduate with professional degree can't be shorter than one year in principle, and the real participation in practical project was needed to solve the specific problems under the help of analysis. The policies issued by Chinese government in 2010 which points out that the universities and colleges should establish long-term, stabilized, practical joint cultivation mechanism with related sections and establish practical bases with multiple formation to ensure the quality of practical training. Most of the current professional practices including two modern: practical vase out of the university and practical bases out of the university. Practical base in the university is enterprises which depend on current basis of research and development and adopted system of double mentors who guide professional practice of postgraduate together. While adopting practical bases and double mentors modern can make student take real participation into process from the development and design to manufacture, and the whole process of the monitor of quality process and the finalization of products as well. The analysis and solving of specific problems make postgraduate comprehensively understand the condition of related business and industry which leads to better result of professional practical effectiveness. But there are some problems to be solved in the practical base out of the university in terms of worries such as security and management to students. Many enterprises are not fully responsible which leads to the low positive of practical bases construction; furthermore, there is no clear obligation between the university mentor and enterprises mentor so the better cooperation and coordination can't be implemented in guiding postgraduate which leads to many students dissociate between university and enterprises. The rapid growing quantity of full-time postgraduate with professional degree needs more mentors of enterprises to satisfy the needs of students to get postgraduate education. And practical bases of enterprises do not have obligations to cultivate such amounts of mentors. University and colleges are now realized that to bring the whole society and enterprises into the cultivation process of full-time postgraduate with professional degree is a big challenge. So active construction of practical bases are now begin 
which is gradually become the important measures to the practical ability cultivation of full-time postgraduate with professional degree which contains two reasons: Firstly, the evaluation and promotion is still academic scientific research oriented. Under the pressure of academic results, many mentors have to pay more attention to the academic research which is easily to develop research result. Secondly, most of the teachers of universities and colleges never set foot in the work of related practical areas who know academic theory only and without engineering practical experience, so it's hard for them to take the responsibility of cultivating students in term of their practical ability.

\section{Solutions of ensuring high quality of professional practical link}

Bases of enterprises can only be the assistance party to expend professional practical link instead of the leading party to the professional practical link of full-time postgraduate with professional degree based on the current problems in the professional practical link of full-time postgraduate with professional degree. The solutions were put forward as following:

\section{Integrating the knowledge and ability needs to create the environment of professional practical teaching}

Most of the full-time postgraduates do not get their hands on the practices and related careers. In order to form and develop professional practical ability, the professional knowledge is necessarily needed. Besides that, postgraduate also needs to know the requirements of careers positions to the knowledge and ability for applied talents. For now, the present condition is not optimistic. Furthermore, Chinese professional degrees were set according to the categories and related areas while the research-type universities generally organize and implement educational and teaching activities in a way of using highly academic subjects and professional institutions as unit based on the scientifically research. A typical example was found in the survey process in term of the industrial construction branch of construction postgraduate which supportive requirement is "Management science and construction" plus some "subject with construction background". But inside of university, either the education of postgraduate with professional degree is in the management institution or in the constructive institution. Firstly, it leads to the different subject background of applicant sources due to the influences of studying subject types and subject degree type will make fresh graduate applicants from different majors to choose differently in term of registration. Secondly, it also will lead to the differences of teachers between knowledge selection and ability requirement due to the difference between subject in dominant positions and its related career area. Aforementioned different applied in the applied areas as well. The professional knowledge background, subject belonging, the experience of academics and work will deeply influence the connection between the organization of knowledge content and construction of knowledge and practice. Thus, serious consideration should be put in the big amount of current existing cultivated mode which based on professional institution to organization and implementation of professional postgraduate. How to transform traditional subject education to the research-area-oriented education which characteristics are the integration of knowledge, openness, complexity is an important problem to improve the cultivated quality of full-time postgraduate with professional degree. 


\section{Enhancement of across-subject education and "professional generalized knowledge education in related area"}

In order to introduce student to the front line of its studied subject, education of postgraduate in China is subject centered to organize and emphasize the subjectivity, technicality and systematically for a long time. Essentially speaking, the full-time postgraduate needs integration of practical knowledge and professional knowledge. But such type of knowledge will meet strong resistance of specialization of subject knowledge and academic inertial forces of research type university when it was enrolled in subject curriculum. We found that in one research type university, many professional postgraduate curriculum was set together with academic postgraduate curriculum. Some of professional postgraduate courses are the lower edition or the deleted edition of academic postgraduate courses. There is no specialized curriculum was developed for full-time professional postgraduate. From the constructive condition of cultivated system of full-time professional postgraduate, most of the researching type universities focus on the professional practical modern. They practice for the sake of practice which means the separation between curriculum construction and major practice. From the perspective of relationship between knowledge and ability, there are no essential effectiveness if there are no relationship in between reformation of education and teaching and construction of curriculum system. The curriculum reformation is the most difficult and most ignorable link of the full-time postgraduate with professional degree education due to its reformation relates to the adjustment of knowledge system structure and reformation of teaching method. "If the standard of high-level knowledge relates to the value of entrenched interest in dominant position. People is going to see, especially in university, every change relates to the high-level knowledge related to the academic curriculum would meet biggest resistance.” Apart from the fundamental requirements which should be kept in full-time postgraduate curriculum system in term of the postgraduate education to subject knowledge in essential. The other two principles should be embodied which are: subject intercrossed and genera knowledge. This will play a positive role in cultivating students' ability to construct and solve problems, knowledge integration and transfermation.

\section{Universities and colleges should play the main role in professional practice link}

The fundamental mission of universities and colleges is to cultivate the talents, no matter the undergraduate and postgraduate. Universities and colleges will lose its root with the cultivation of talents. The enterprises and public institutions have no obligations to cooperate with universities and colleges in the cultivation of talents, so the important mission of professional cultivation purpose realization in term of full-time postgraduate with professional degree could not be fully depended on the practical base of enterprise. The universities and colleges should independently take the responsibilities to leading work of full-time postgraduate with professional degree cultivation while the practical base of enterprises assist behind.

\section{Universities and colleges should actively cultivate and construct the teaching team which adaptable to the education of full-time postgraduate with professional degree}

On the one hand, the active reformation should be put into evaluation, related supportive policy should be put forward in term of the title of technical post evaluation and recruitment to eliminate the extra worries of teachers and encourage teachers with practical guiding ability to fully committee themself to the guiding work of full-time postgraduate with professional degree; On the 
other hand, applied teachers recruitment system should be established as well to lower the scientifically researching result conditions. By which measures, hoping to introduce researching personal of rich experience and certain degree of theoretical knowledge who explore for improvements in the practice back to the universities and colleges to expand the applied teachers scale. In the mean time, putting forward related policies to encourage actively academic teacher to transform and introducing them to march forward to the engineering areas to improve engineer ability. The universities and colleges should massively cultivate and recruit teacher team with practical guiding ability to satisfy the big scale of need of the education to full-time postgraduate with professional degree from three aforementioned perspectives.

\section{Summary}

The practical bases of enterprises and adoption of double mentors system plays an important role in the current stage of full-time postgraduate with professional degree due to seriously inadequate teacher team with practical guiding ability in universities and colleges. But in the long term, the talents cultivation is still the fundamental mission and cornerstone of universities and colleges. So the active reformation should be put into the evaluation system, recruitment system and mentors cultivating system by universities and colleges. The teachers team which can adopt to the full-time postgraduate with professional degree should be independently established to play an major role in the education of full-time postgraduate with professional degree.

\section{Acknowledgment}

This research was financially supported by: 2017BJJ075; 2018-ZZJH-616; 182400410151.

\section{References}

[1] Wang Yao, Huang jianye, Song chunlin, professional degree graduate student off-campus practice base construction of exploration and practice ,J. China electronics education. (01).

[2] Qu Wei, Xia Jinwen, Song Rui, He Wanliang,2017 full-time professional degree graduate student campus practice base model Xian building university of science and technology, J.Journal of xian building university of science and technology (social science edition), 2017 (01). 